\title{
DURABILITY ANALYSIS OF THE PROTOTYPE TEST RIG FOR MAIN ROTORS
} \author{
Andrej Novák ${ }^{2, *}$ \\ ${ }^{1}$ Lublin University of Technology, Lublin, Poland \\ ${ }^{2}$ University of Zilina, Zilina, Slovakia \\ *E-mail of corresponding author: andrej.novak@fpedas.uniza.sk
}

Karol Ścisłowski ${ }^{1}$, Krzysztof Skiba ${ }^{1}$, Mirosław Wendeker ${ }^{1}$, Rafał Kliza ${ }^{1}$, Ksenia Siadkowska ${ }^{1}$, Tomasz Lusiak ${ }^{1}$,

\section{Resume}

This paper presents an analysis of the strength of a prototype test rig for testing rotors of unmanned aerial vehicles. Digital design software was used for the design work that covered the creation of a virtual model of the test rig and strength analysis of its key elements. The paper discusses the test rig solutions, applied to date, of the small main rotor research. From the assumed operational parameters and structural parameters of the rotor, the main forces acting on the designed structure were determined: lifting force, reaction torque and empty mass of the test rig. Suitable actuators of the control system enabling the regulation of the total pitch and periodic pitch of the rotor, within the full range of the angle of attack, were selected for the rotor under test. The FEM (Finite Element Method) strength analysis was carried out for the proposed support structure and the correctness of the design was verified.

Available online: https://doi.org/10.26552/com.C.2022.2.B148-B157

\section{Article info}

Received 7 May 2021

Accepted 16 December 2021

Online 22 February 2022

\section{Keywords:}

FEM

digital design

rotors

CFD (Computational Fluid

Dynamics)

aircraft

ISSN 1335-4205 (print version)

ISSN 2585-7878 (online version)

\section{Introduction}

The development of computer technology, artificial intelligence and miniaturisation in the broadest sense of the word, make the market for autonomous vehicles and unmanned remotely controlled vehicles grow rapidly. Such vehicles are used when performing certain tasks by humans is impossible, uneconomical or too dangerous. Rescue services, the police and the military are increasingly interested in unmanned vehicles and aircraft. The smaller size of an aircraft makes it more difficult to detect, increases its manoeuvrability and reduces the costs of combat and reconnaissance missions [1].

Before a new aircraft is introduced to the market, a number of simulation and bench tests are required. Numerical analyses require advanced computational models to illustrate the operation of selected subsystems [2-3], while the bench tests require the construction of test rigs enabling stationary testing of conceptual solutions before their application in flight [4-5]. The preparation of the test bench is an extensive process requiring design of the new components and development of metering to achieve conditions as close as possible to real ones.

The introduction of a new rotor design for an aircraft requires a wide range of simulation and bench tests. Aerodynamic phenomena affecting the rotor structure, as well as forces and moments acting on it, assume a very complex system, variable in time [6]. The simulation study of rotorcraft performance using the CFD method provides approximate values of the lift force or torque applied to the rotor. However, it does not take into account dynamic deformations of rotor blades resulting from aerodynamic forces, inertia forces or the impact of the rotor control system [7] and they can significantly affect the operation of the rotor in real conditions. The paper [8] presents the application of the co-simulation method in aerodynamic calculations of a main rotor of an unmanned helicopter. The authors presented a model based on computer simulations to create a virtual laboratory for performing static and dynamic analyses. It is possible to analyse the rotor blade deformation using the FEM (Finite Element Method) and then import the resulting model into the CFD simulation, but this approach does not cover issues related to mechanical vibrations, pressure pulsations or transient flows [9]. A solution may be a coupled FEM analysis in which the fluid flow affects the mechanical deformation of the components that, in turn, changes the nature of the flow. Such analyses are, however, very time-consuming, especially as many tests are required to simulate all the major operating states of the rotor. Computer simulations allow an initial determination of rotor parameters but cannot fully replace the bench testing. 
Carrying out a bench testing of main rotors is very problematic. The main difficulty is to obtain conditions similar to those that will be encountered during the real flights. The rotor installed on the test rig is not unaffected by aerodynamic effects of both the ground and the structure of the test rig itself [10]. This may cause a discrepancy between the results obtained and the actual performance of the structure that it will achieve in later use. Simulating horizontal flight additionally requires the rotor structure to be placed in a wind tunnel [11]. The paper [12] presents results of a tunnel test for a helicopter main rotor blade model. The blade was sectioned to optimise the angle of attack along the rotor radius. One of the main issues under consideration in the rotor design is vibration [13]. The specification of general and periodic rotor pitch control forces torsional and linear vibrations of rotor blades. In addition, blades are subjected to periodic deflection in the horizontal plane and in the plane of rotation [14]. In an aircraft, the rotor and fuselage are the two systems that interact due to mechanical vibrations and aerodynamic interference [15]. It is therefore necessary to learn exactly the characteristics of the resulting vibrations to prevent resonance from occurring. Various methods of measuring the vibration of the main rotor blades have been used in previous research. The most common is the optical method, using a set of two cameras [16] and markers need to be placed on blade surfaces. Blade deformation was also measured by means of a laser [17] or the Stereo-Cam system, which combines a camera system with laser measurement [18]. Measurement methods based on analysis of acoustic pressure changes at different locations in the blade profile were also used to study air vibrations on the rotor blade surface [19]. Loads acting on the aircraft powerplant and related with loads of the propeller blade are also investigated to develop a model of an aircraft flight envelope, which can contain data to determine the boundary conditions of this model [20].

Following the previous research into the bench testing of main rotors, the main characteristics of the test rig can be determined. Basic parameters, such as a rotor drive, should be calculated from the operational assumptions of the rotorcraft [21]. The fundamental design aspect is to achieve the minimum aerodynamic disturbance [22-23]. The design of the test rig should ensure a free flow of air that does not generate turbulence and unnecessary resistance [24]. The rotor should be installed in such a way to minimise the influence of the earth on its operation [25]. Furthermore, the stiffness of the structure should be selected so that its natural frequency does not coincide with any of the harmonic frequencies generated by the rotor or the control system [26-27].

\section{Methodology}

The article involves the construction of a test rig for testing a helicopter rotor model with variable geometry blades. The test rig consists of a three-bladed main rotor, an articulated control head, a measuring apparatus, a rotor drive system and a frame as a support structure. The design of the test rig was based on the assumed operational (Table 1) and structural (Table 2) parameters of the rotor.

To calculate the rated power that is required to drive the rotor, the rotor efficiency factor of $\eta=0.74$ for this rotor must be taken into account. The rated power is calculated from the formula:

$$
N_{n}=\frac{1}{n} T \sqrt{\frac{T}{2 \delta_{H} A_{m r}}},
$$

where:

$N_{n}$ - required motor rated power,

$\eta$ - rotor efficiency ratio,

$T$ - rotor load capacity,

$\delta_{H}$ - air density,

$A_{m r}$ - area of the main rotor.

For the assumed rotor operating parameters (Table 1), the motor rated power is:

$$
\begin{aligned}
& N_{n}=\frac{1}{0.74} \cdot 1471 N \cdot \sqrt{\frac{1471 N}{2 \cdot 1.22 \frac{\mathrm{kg}}{\mathrm{m}^{3}} \cdot 3.14 \mathrm{~m}^{2}}}= \\
& =27.5 \mathrm{~kW} .
\end{aligned}
$$

To obtain the power consumption characteristics

Table 1 Operating parameters of the test rotor

\begin{tabular}{clc}
\hline Designation & Definition & Value \\
\hline $\mathrm{T}_{0}$ & Outdoor temperature operating range & $287-347 \mathrm{~K}$ \\
$\mathrm{a}_{0}$ & Range of sound speed & $328-347 \mathrm{~m} / \mathrm{s}^{-1}$ \\
$\rho$ & Air density & $0.875-1.225 \mathrm{~kg} / \mathrm{m}^{-3}$ \\
$\mu$ & Kinetic viscosity of air & $14.7 \cdot 10^{-5}$ \\
$\mathrm{~V}_{\mathrm{d}}$ & Maximum flight speed $\mathrm{h}=0 \mathrm{~km} \mathrm{ISA}$ & $130 \mathrm{~km} / \mathrm{h}$ \\
$\mathrm{V}_{\mathrm{ne}}$ & Never exceeded speed $\mathrm{h}=0 \mathrm{~km} \mathrm{ISA}$ & $150 \mathrm{~km} / \mathrm{h}$ \\
$\omega_{\max }$ & Maximum rotor speed & $1801 / \mathrm{s}$ \\
$\omega_{\min }$ & Minimum rotor speed & $1001 / \mathrm{s}$ \\
$\mathrm{T}$ & Rotor load capacity & $150 \mathrm{~kg} / 1471 \mathrm{~N}$ \\
\hline
\end{tabular}


Table 2 Design parameters of the rotor

\begin{tabular}{lc}
\hline Parameter & Value \\
\hline Range of motion on longitudinal control & $+/-7 \mathrm{deg}$ \\
Range of motion on transverse control & $+/-4 \mathrm{deg}$ \\
Range of motion on overall pitch control & $+/-12 \mathrm{~mm}$ \\
Distance of the vertical pivot joint from the axis of rotation & $50 \mathrm{~mm}$ \\
Distance of the horizontal pivot joint from the axis of rotation & $78 \mathrm{~mm}$ \\
Angle of advance control & $30 \mathrm{deg}$ \\
Fluctuation compensation & 0.3 \\
Type of deflection damper & Elastomer \\
Damping characteristics & Linear \\
Range of blade angle of attack values at 0.7 R & $0-20 \mathrm{deg}$ \\
Rotor disc fill factor & 0.0668 \\
Assumed value of the rotor boundary losses & $0.96 \%$ \\
Mechanical losses & $0.85 \%$ \\
Rotor Efficiency Ratio & 0.74 \\
\hline
\end{tabular}

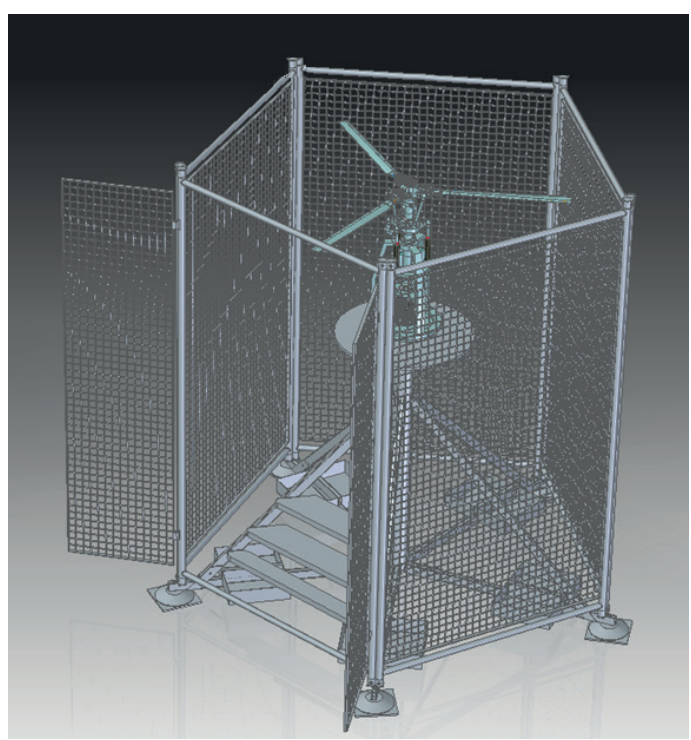

Figure 1 Test rig for the main rotor

of the rotor, it is necessary to use a measuring system with an appropriate measuring range. The power will be determined from measurements of the rotor angular velocity and transmitted torque. Its value is calculated by transforming the formula:

$$
N_{n}=\frac{M \cdot n}{9550} \text {, }
$$

where:

$M$ - rotor torque,

$n$ - rotor speed.

The maximum torque achieved for the assumed operating conditions (Table 1) is respectively

$$
M=\frac{N_{n} \cdot 9550}{\frac{30 \omega}{\pi}}=\frac{27.5 k W * 9550}{\frac{30 \cdot 180 \frac{\mathrm{rad}}{\mathrm{s}}}{\pi}}=152.7 \mathrm{Nm} .
$$

The calculated value will be taken into account during the construction of the measuring system (selection of measuring transducers) and strength calculations of the rig frame. The bench requires a motor with a power of more than $27.5 \mathrm{~kW}$.

\section{Result}

\subsection{Test rig design}

The test rig was designed with the Solid Edge 2021 $\mathrm{CAD}$ software. The plane of rotation of the blades was assumed at a height of not less than $2.5 \mathrm{~m}$ to ensure that the impact of the ground on the air flow indexed by the rotor is minimised. The test rig should also be able to add ballast mass to improve its stability. For safety reasons, a rotor cover made of steel mesh was assumed. The test rig is shown in Figure 1. In the place of connection of the rotor carrying the frame and the rig supporting the structure, a six-component balance was 


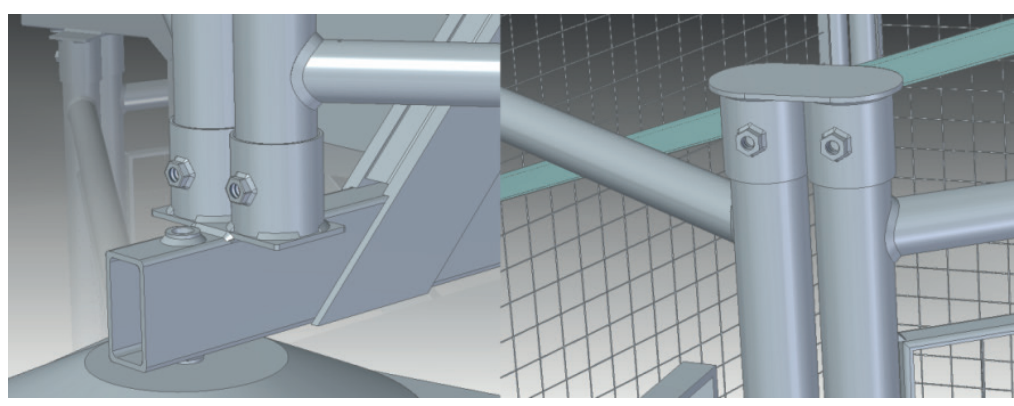

Figure 2 Method of connecting the panelled covers

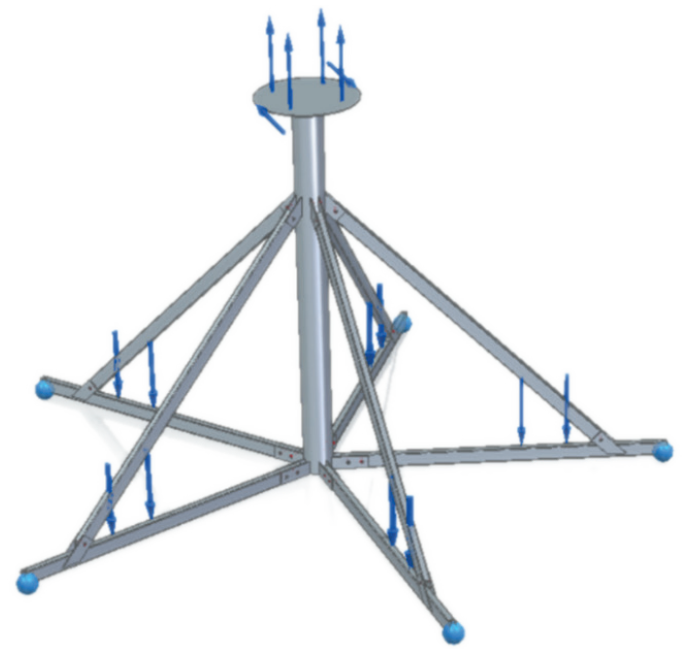

Figure 3 Distribution of the forces and restraints acting on the rig structure

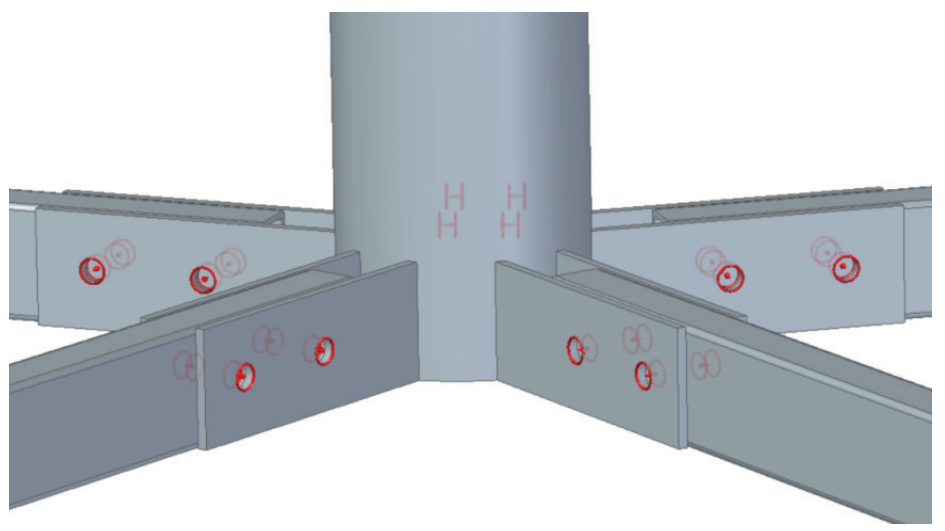

Figure 4 Bolted connection points

applied to measure forces and moments acting in the three axes of the coordinate system.

In the design, the rotor plane of rotation is at a height of $2.8 \mathrm{~m}$. The base is placed on vibrationisolated bases and at each base, pockets for additional load were installed to stabilise the rig. The rig cover was designed in such a way to be quickly dismantled for maintenance and service works, Figure 2.

\subsection{FEM strength analysis}

The strength analysis was carried out using the NX Nastran tool, built into the Solid Edge 2021 software.
The correctness of the rig design was confirmed by an FEM analysis of its most important elements. For this purpose, the model was simplified. Hinged restraints were provided at the vibration isolator mounting points. Appropriate boundary conditions were given for the support points of the construction. As there are no lateral forces acting on the structure, the whole movement is blocked at one base support. The remaining supports are allowed to move in the horizontal plane. All the supports can rotate about the three axes of the coordinate system. The holes have been given connections with the tool for creating bolted joints. A zero internal friction connection is assumed. The structure was loaded with the lifting force generated by the rotor $(1500 \mathrm{~N})$, rotor reaction 


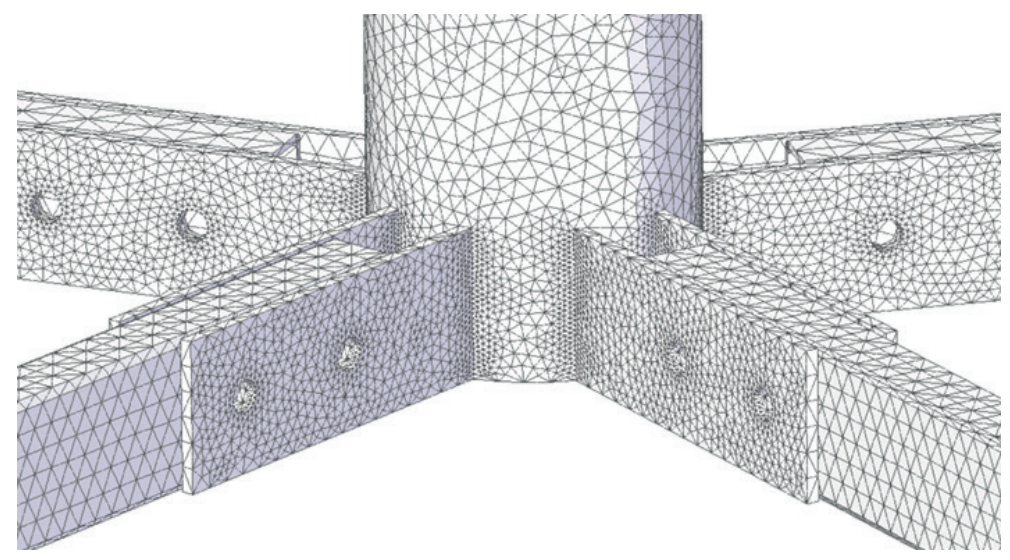

Figure 5 Grid generated for the model

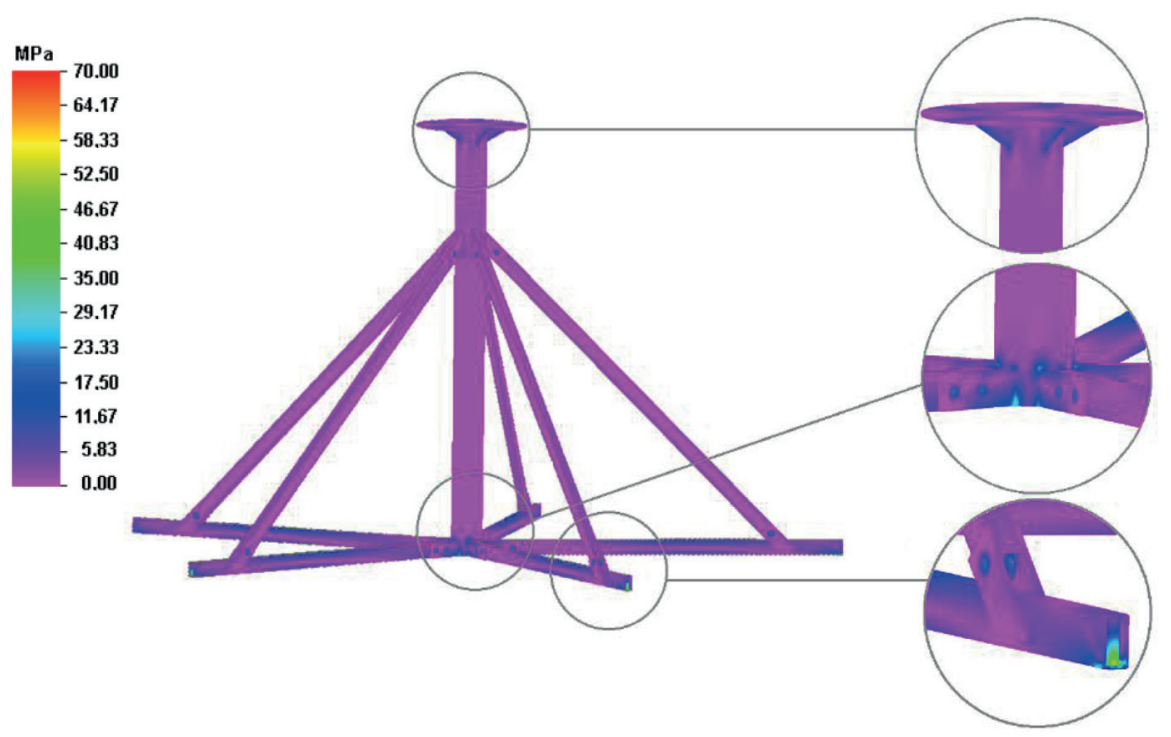

Figure 6 Results of the strength analysis

torque $(200 \mathrm{Nm})$, ballast $(5 \times 600 \mathrm{~N})$ and the gravity force of the station. The distribution of the forces on the structure is shown in Figure 3. The material chosen for the analysis of the structure is an alloy-free structural steel for which the yield strength is $262 \mathrm{MPa}$, see Figure 4.

A tetrahedral mesh with a maximum wall size of $10.13 \mathrm{~mm}$ was generated. The grid was compacted in the screw connections and welded joints of the individual elements of the rig structure. The computational grid was of 242,488 elements. The layout of the grid on the more important elements of the structure is presented in Figure 5. The simulation was carried out for the static stresses in the structure and forces arising in the bolted connections. Figure 6 shows the results of the analysis.

The highest recorded stresses occurred at the mounting points of the vibration isolation supports (Figure 7) and amounted to 66.53 $\mathrm{MPa}$ (Figure 8). The stresses also concentrated at the bolted connections and at the lower mounting points of the supports to the central column (Figure 9). The highest shear force that was measured in the bolted connection was $449 \mathrm{~N}$ and caused a shear stress of $5.75 \mathrm{MPa}$. The maximum torsional moment acting on the bolts as a result of loading the structure was $10.57 \mathrm{Nm}$. The torsional stress on the bolt was $8 \mathrm{MPa}$. Both torsional and shear stresses in the bolted connection did not exceed the allowable values.

\subsection{Structure optimisation}

Due to the high stresses in the base of the structure, it was decided to modify the design to limit the maximum stress values. The surface area of the brackets attaching the base to the central column was increased and steel washers were used at the vibration isolator mounting points in Figure 10. Following these design changes, the model was re-analysed for strength.

The modifications allowed for a significant reduction in stresses in the areas of connection of the base brackets with the central column of the rig. The maximum stress in this area did not exceed $19.73 \mathrm{MPa}$, see Figure 11.

The use of a steel washer at the mounting point of the vibration isolation bases caused the stresses to dissipate and be transferred from the welded joint of the sleeve to the lower part of the profile. The maximum stress at this point was reduced to $60.22 \mathrm{MPa}$, see Figure 12 . 


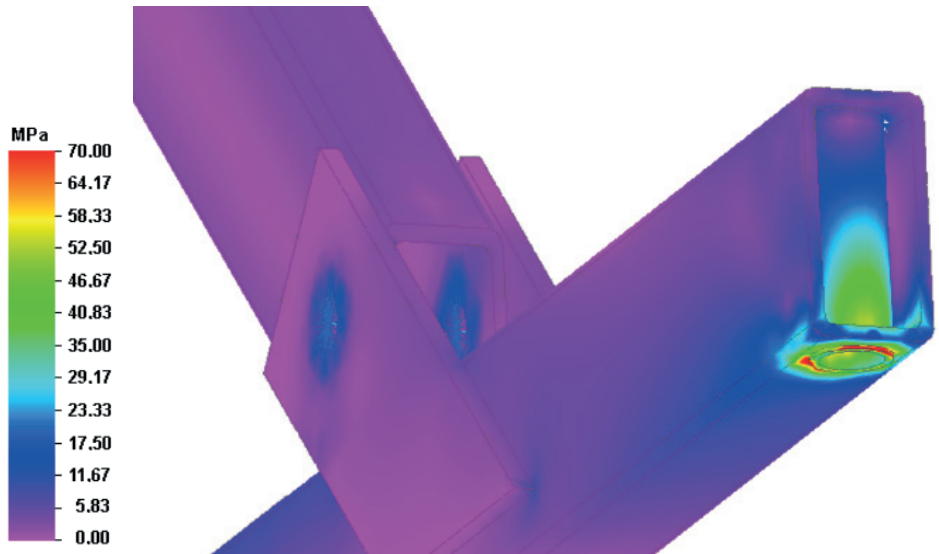

Figure 7 Area of the highest concentrated stress in the material
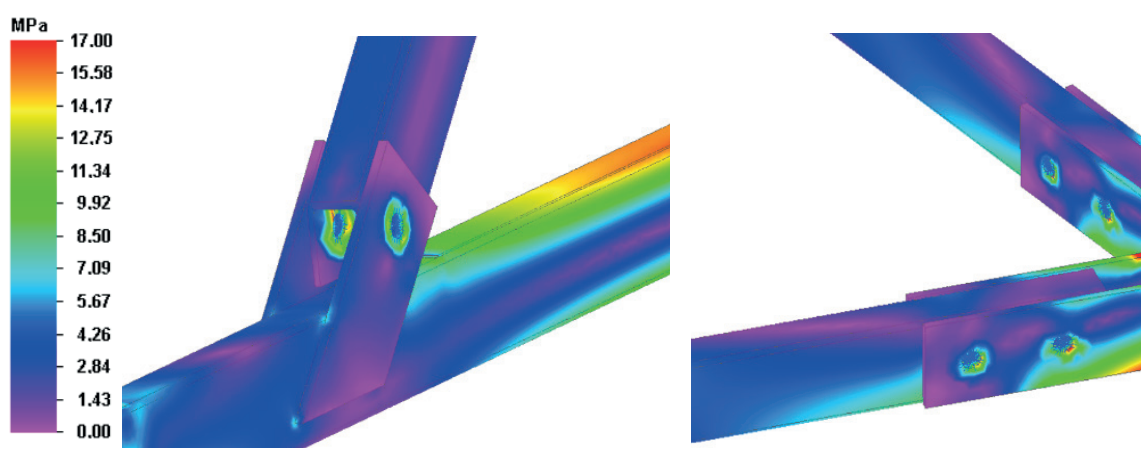

Figure 8 Stress distribution at the bolted connections

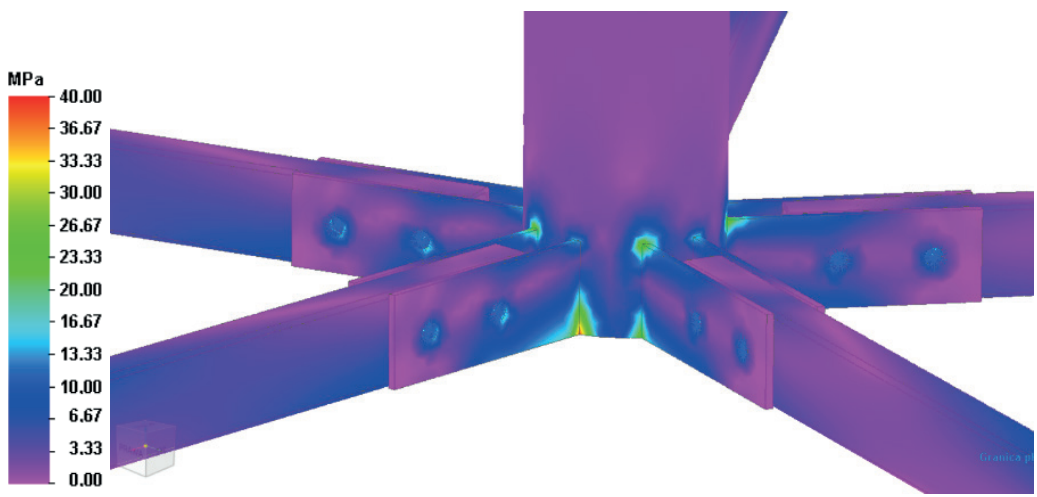

Figure 9 Areas of the concentrated stress in the lower part of the base
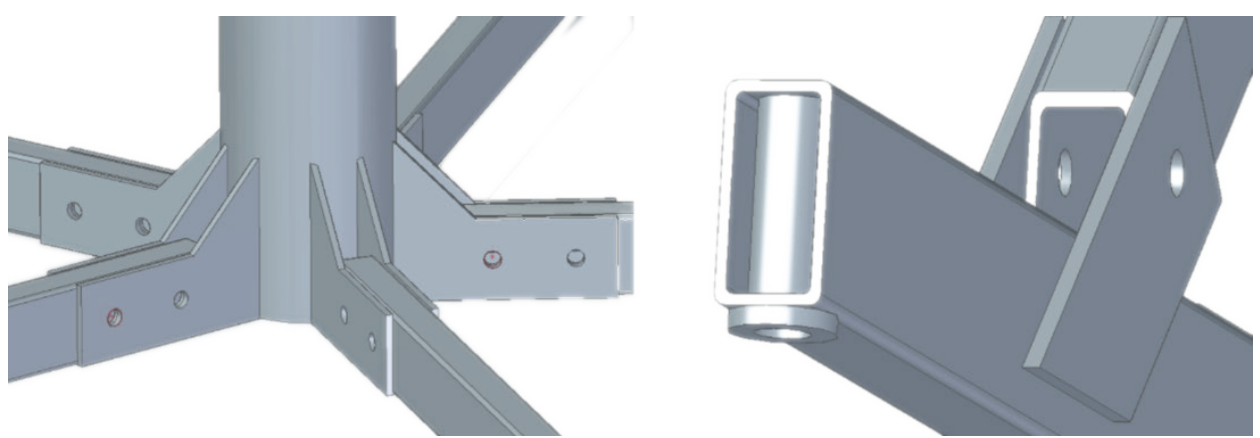

Figure 10 Structure modifications 


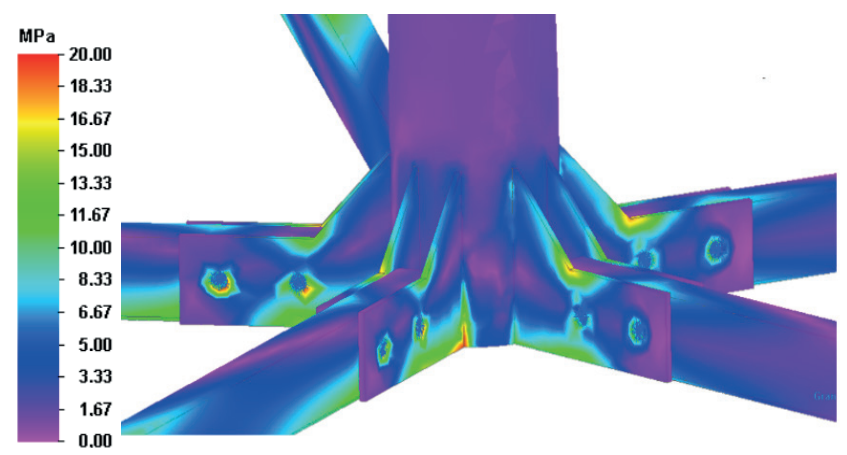

Figure 11 Stress distribution in the modified base

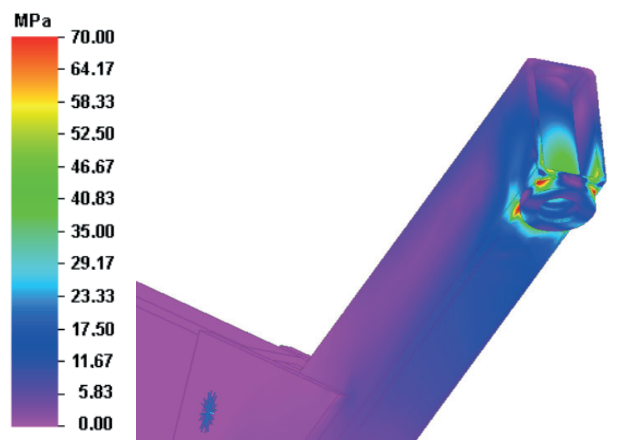

Figure 12 Stress distribution in the modified rig base
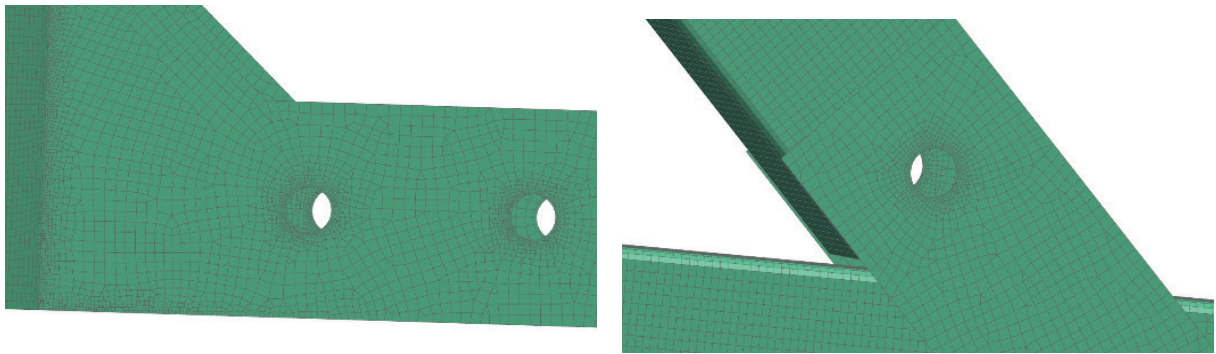

Figure 13 Grid view on the model

In order to verify the applicability of the obtained results, a comparative analysis of the most heavily loaded bench components using the thin-walled element method was carried out. The analysis was conducted using the NX Nastran environment of the NX 12 software (Figure 13). A central surface was created for the walls of thin-walled elements, on which a grid with a global size of one element of $3 \mathrm{~mm}$ was applied. The thickness of the mesh was set according to the parameters of the analyzed elements (from 2 to $5 \mathrm{~mm}$ ). The mesh was concentrated at the bolted and welded joints, giving a local mesh element size of $0.5 \mathrm{~mm}$. A tetrahedral mesh with a maximum element size of $0.5 \mathrm{~mm}$ was used to analyze the element fixing the vibration isolator to the rig base.

Material data consistent with previous analyses were introduced into the structure, as well as a mass point to load and represent the mass of repetitive elements of the stand, which were not considered in this part of the analysis. The maximum stress, occurring at the welded joint between the central column and the base brackets, was $30.93 \mathrm{MPa}$. The concentration of stresses occurred at the point of collapse of the grip part. The maximum stress at this point was $38.87 \mathrm{MPa}$ (Figure 14).

At the point of fixing the vibration isolator to the base, the maximum stress was $53.86 \mathrm{MPa}$ (Figure 15). The stresses were uniformly distributed, at no place exceeding the permissible stresses.

In the places where the angled stiffening bars are fixed to the stand structure, the maximum stresses are in the range of $15 \div 19 \mathrm{MPa}$ (Figure 16). The stress concentration occurs in the places of welded joints and bolted joints, but the stresses do not exceed the permissible values.

\section{Discussion}

The designed structure of the rig is correct in terms of the static strength. The design modifications resulted in a more uniform distribution of stresses at critical points of the structure and a reduction in their maximum values. In none of the cases considered did the stresses 


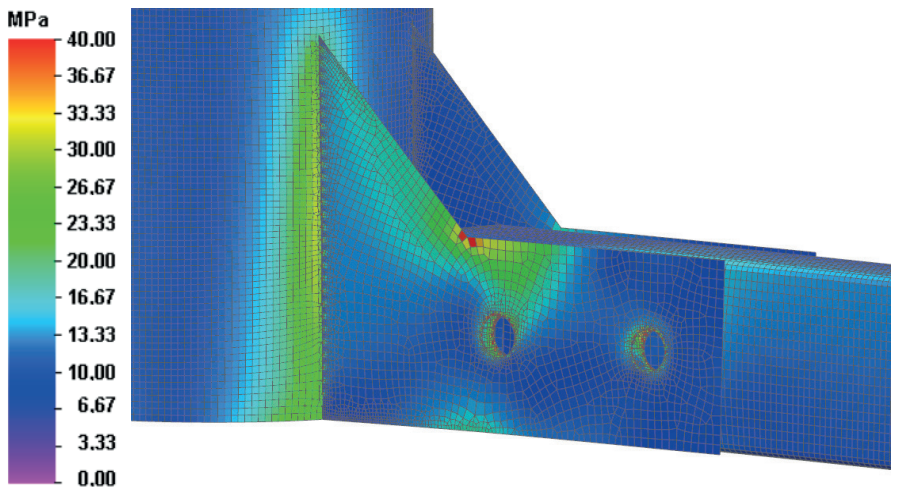

Figure 14 Stress distribution in the grip section and in the central column
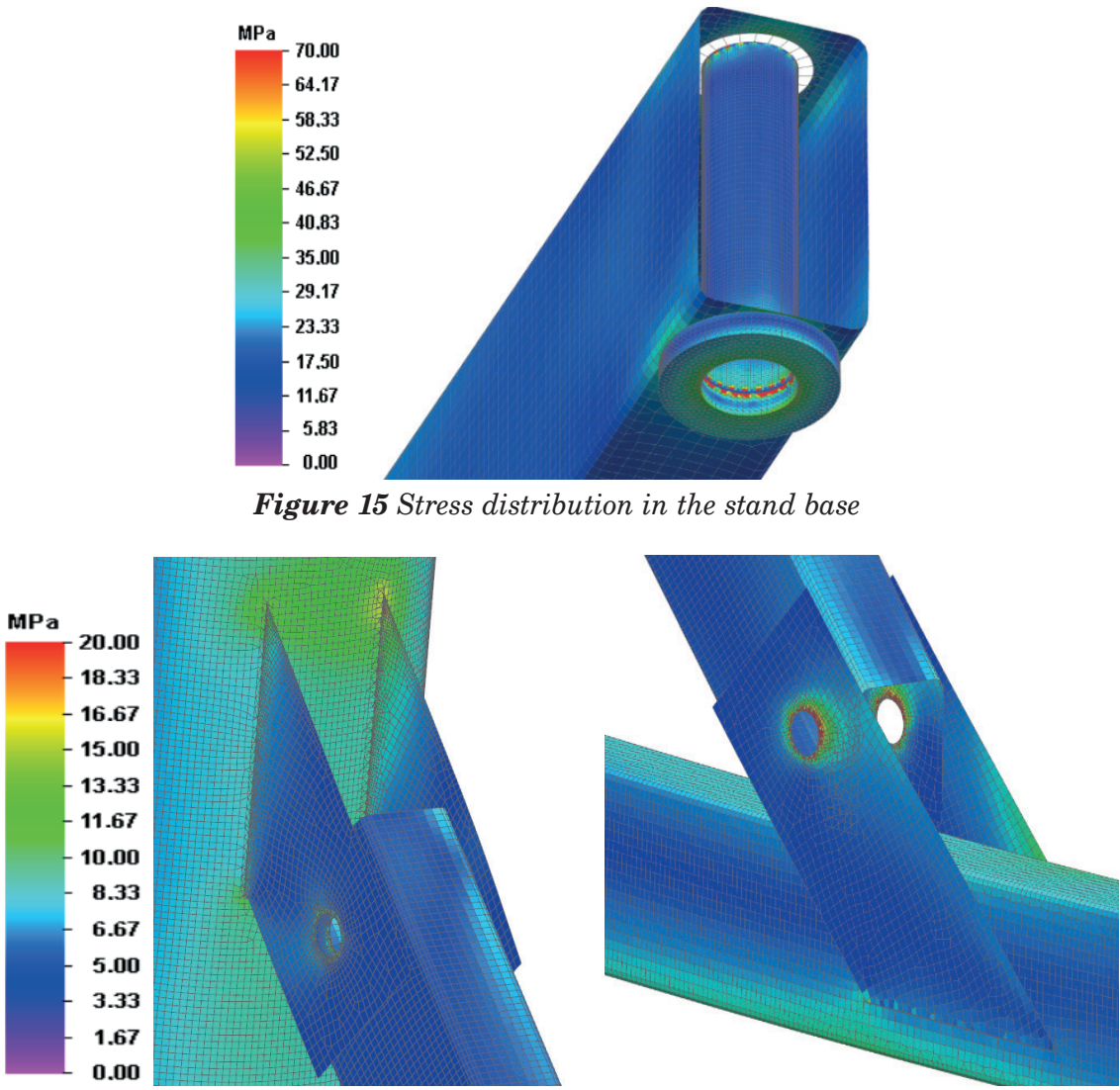

Figure 16 Stress distribution in the gripping elements of the stiffening bar

exceed the yield strength of the steel. The comprehensive measurement technologies make the designed structure of the rig ideally suited to fundamental research, as well as applications in industry. The system is completely portable; tests can be performed in any wind tunnel of sufficient size, anywhere in the world.

Determination of the natural frequencies of vibrations for individual components could enable the introduction of such design changes to prevent the occurrence of resonance between the rotor and the supporting structure of the rig. The uncontrolled increase of the vibration amplitude is very dangerous for the supporting rotor due to large masses and moments of inertia and at the same time the low vibration damping factor of the structure. These measurements are taken to determine the power requirements, rotor and blade dynamics, as well as the high-resolution rotor blade and fuselage aerodynamics. External measurement technologies can be used to calculate noise emissions and localise noise sources, as well as to visualise the global flow field and individual vortex structures. However, for the whirlwind field testing it is necessary to analyse the aerodynamic flow overlay of the designed rig in the flow direction as stated in source [6] and in line with the sample calculation according to source [12].

\section{Conclusions}

Results of this proposal proved the validation of the test rig computer design for testing a helicopter rotor with a variable rotor blade geometry. The proposed 
design was based on the most used version of 3 blade main rotor. The computer analysis output also proved to be suitable for the two and four blade main rotors with a variable geometry system. The test rig prototype was also designed for UAV and gyrocopters. The application use of Solid Edge 2021 CAD or NX Siemens PLM Software is sufficient mainly in the initial phase of research or of modelling any prototype design. This software helped to discover the possible critical points on the constructions that could be affected by vibrations. The authors' future research will lead to modelling of an aerodynamic cover for the test rig and furthermore to developing suitable conditions for measurement of selected variables.

\section{Acknowledgments}

This work has been financed by the National Centre for Research and Development under the LIDER program. Grant Agreement No. LIDER/45/0177/L-9/17/ NCBR/2018.

\section{References}

[1] SINGH, R., BHUSHAN, B. Data-driven technique-based fault-tolerant. IEEE Transactions on Instrumentation and Measurement [online]. 2021, 70, 3502711. ISSN 0018-9456, eISSN 1557-9662. Available from: https://doi. org/10.1109/TIM.2020.3025656

[2] RACZYNSKI, R., SIADKOWSKA, K. Numerical analysis issues in the evaluation of the helicopter' s main rotor stability. Journal of Physics: Conference Series [online]. 2021, 1736, 012016. ISSN 1742-6588, eISSN 1742-6596. Available from: https://doi.org/10.1088/1742-6596/1736/1/012016

[3] SIADKOWSKA, K., BOROWIEC, P. Strength analysis of the conceptual model of a main rotor blade spar with actuators. Journal of Physics: Conference Series [online]. 2021, 1736, 012021. ISSN 1742-6588, eISSN 1742-6596. Available from: https://doi.org/10.1088/1742-6596/1736/1/012021

[4] CZARNIGOWSKI, J. A., JAKLINSKI, P., SCISLOWSKI, K., REKAS, D., SKIBA, K. The use of a low frequency vibration signal in detecting the misfire of a cylinder of an aircraft piston engine. SAE Technical Paper [online]. 2020, 2020-01-2023. ISSN 0148-7191, eISSN 2688-3627. Available from: https://doi.org/10.4271/2020-01-2023

[5] SYTA, A., CZARNIGOWSKI, J., JAKLINSKI, P. Detection of cylinder misfire in an aircraft engine using linear and non-linear signal analysis. Measurement [online]. 2021, 174, 108982. ISSN 0263-2241. Available from: https://doi.org/10.1016/j.measurement.2021.108982

[6] BERNARDINI, G., PORCELLI, R., SERAFINI, J., MASARATI, P. Rotor blade shape reconstruction from strain measurements. Aerospace Science and Technology [online]. 2018, 79, p. 580-587. ISSN 1270-9638. Available from: https://doi.org/10.1016/j.ast.2018.06.012

[7] NING, T., WEI, F. S. Chaotic behavior of helicopter servo-flap vibratory data during different flight conditions. In: 1st International Congress on Image and Signal Processing CISP 2008: proceedings [online]. IEEE. Vol. 3. 2008. ISBN 978-0-7695-3119-9, p. 108-112. Available from: https://doi.org/10.1109/CISP.2008.643

[8] SIADKOWSKA, K., RACZYNSKI, R., WENDEKER, M. Numerical analysis of the rotor in the co-simulation methodology. IOP Conference Series: Materials Science and Engineering [online]. 2019, 710, 012009. ISSN 17578981, eISSN 1757-899X. Available from: https://doi.org/10.1088/1757-899X/710/1/012009

[9] MA, Y. Y., ZHAO, Q. J., CHEN, X., ZHAO, G. Q. Experimental analyses of synthetic jet control effects on aerodynamic characteristics of helicopter rotor. Aeronautical Journal [online]. 2020, 124(1274), p. 597-616. ISSN 0001-9240, eISSN 2059-6464. Available from: https://doi.org/10.1017/aer.2019.163

[10] MEHRABI, A., DAVARI, A. R. Outwash flow measurement around the subscale tandem rotor in ground effect. Engineering Science and Technology, an International Journal [online]. 2020, 23(6), p. 1374-1384. ISSN 22150986. Available from: https://doi.org/10.1016/j.jestch.2020.08.016

[11] KOTTAPALLI, S., RUSSELL, C. R., ACREE, C. W., NORMAN, T. R. Aeroelastic stability analysis of a full-scale isolated proprotor on the tiltrotor test rig. In: AIAA Scitech 2019 Forum: proceedings [online]. 2019. Available from: https://doi.org/10.2514/6.2019-2134

[12] SIADKOWSKA, K. Aerodynamic measurement of the rotor blade for aviation application. In: 2020 IEEE 7th International Workshop on Metrology for AeroSpace MetroAeroSpace 2020: proceedings [online]. 2020. p. 610614. Available from: https://doi.org/10.1109/MetroAeroSpace48742.2020.9160131

[13] LEE, Y. L., KIM, D. H., PARK, J. S., HONG, S. B. Vibration reduction simulations of a lift-offset compound helicopter using two active control techniques. Aerospace Science and Technology [online]. 2020, $106,106181$. ISSN 1270-9638. Available from: https://doi.org/10.1016/j.ast.2020.106181

[14] CASTILLO-RIVERA, S., TOMAS-RODRIGUEZ, M. Helicopter modelling and study of the accelerated rotor. Advances in Engineering Software [online]. 2018, 115, p. 52-65. ISSN 0965-9978. Available from: https://doi. org/10.1016/j.advengsoft.2017.08.012 
[15] YUAN, Y., CHEN, R., LI, P. Trim investigation for coaxial rigid rotor helicopters using an improved aerodynamic interference model. Aerospace Science and Technology [online]. 2019, 85, p. 293-304. ISSN 1270-9638. Available from: https://doi.org/10.1016/j.ast.2018.11.044

[16] SOUSA, P. J., BARROS, F., TAVARES, P. J., MOREIRA, P. M. G. P. Experimental and numerical analysis of deformation in a rotating RC helicopter blade. International Journal of Turbomachinery, Propulsion and Power [online]. 2020, 5(3), 13. eISSN 2504-186X. Available from: https://doi.org/10.3390/IJTPP5030013

[17] GARDNER, A. D., WOLF, C. C., RAFFEL, M. Review of measurement techniques for unsteady helicopter rotor flows. Progress in Aerospace Sciences [online]. 2019, 111, 100566. ISSN 0376-0421. Available from: https://doi. org/10.1016/j.paerosci.2019.100566

[18] ZAPPA, E., LIU, R., TRAINELli, L., FERRARIO, A., CORDISCO, P., TERRANEO, M., GRASSETTI, R., REDAELLI, M. Laser and vision-based measurements of helicopter blade angles. Measurement: Journal of the International Measurement Confederation [online]. 2018, 118, p. 29-42. ISSN 0263-2241. Available from: https:// doi.org/10.1016/j.measurement.2017.12.037

[19] DONG, Z., LIANG, L., ZHANG, W., JIAO, L., PENG, D., LIU, Y. Simultaneous pressure and deformation field measurement on helicopter rotor blades using a grid-pattern pressure-sensitive paint system. Measurement: Journal of the International Measurement Confederation [online]. 2020, 152, 107359. ISSN 0263-2241. Available from: https://doi.org/10.1016/j.measurement.2019.107359

[20] GRABOWSKI, L., CZYZ, Z., PORZAK, M. The study on loads on an aircraft piston engine Continental Motors IOF-240-B5B in training flights. Transport [online]. 2018, 33(3), p. 773-778. ISSN 1648-4142, eISSN 1648-3480. Available from: https://doi.org/10.3846/transport.2018.5467

[21] ZHANG, Y., JIANG, C., WANG, Y., SUN, F., WANG, H. Design and application of an Electric Tail Rotor Drive Control (ETRDC) for helicopters with performance tests. Chinese Journal of Aeronautics [online]. 2018, 31(9), p. 1894-1901. ISSN 1000-9361. Available from: https://doi.org/10.1016/j.cja.2018.07.007

[22] BARDERA, R., MATIAS, J. C., GARCIA-MAGARINO, A. PIV helicopter rotor-ground and rotor-frigate interaction study. In: AIAA Aviation 2020 Forum: proceedings [online]. 2020. p. 1-22. Available from: https://doi. org/10.2514/6.2020-2740

[23] PECHO, P., AZALTOVIC, V., KANDERA, B., BUGAJ, M. Introduction study of design and layout of UAVs 3D printed wings in relation to optimal lightweight and load distribution. Transportation Research Procedia [online]. 2019, 40, p. 861-868. ISSN 2352-1465. Available from: https://doi.org/10.1016/j.trpro.2019.07.121

[24] TANG, Q., ZHANG, R., CHEN, L., XU, G., DENG, W., DING, C., XU, M., YI, T., WEN, Y., LI, L. High-accuracy, high-resolution downwash flow field measurements of an unmanned helicopter for precision agriculture. Computers and Electronics in Agriculture [online]. 2020, 173, 105390. ISSN 0168-1699. Available from: https:// doi.org/10.1016/j.compag.2020.105390

[25] CERNAN, J., PECHO, P., CUTTOVA, M., SEMRAD, K. Structural analysis of centrifugal compressor impellers with different blade shapes. In: International Conference Transport Means: proceedings. 2018. p. 972-977.

[26] LYU, W. L. Method for eliminating aerodynamic lift vibration of rigid rotor helicopters based on the novel sinetrim model. Aerospace Science and Technology [online]. 2020, 98, 105655. ISSN 1270-9638. Available from: https://doi.org/10.1016/j.ast.2019.105655

[27] SEDLACKOVA, A. N., KURDEL, P., LABUN, J. Simulation of unmanned aircraft vehicle flight precision. Transportation Research Procedia [online]. 2020, 44, p. 313-320. ISSN 2352-1465. Available from: https://doi. org/10.1016/j.trpro.2020.02.037 